\title{
Histone lysine methacrylation is a dynamic post- translational modification regulated by HAT1 and SIRT2
}

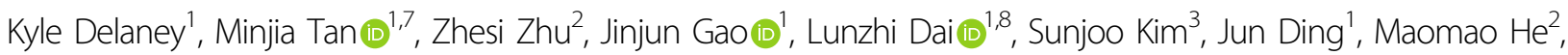 \\ Levon Halabelian (10), Lu Yang ${ }^{4}$, Prabakaran Nagarajan ${ }^{5}$, Mark Robert Parthun ${ }^{5}$, Sangkyu Lee, Saadi Khochbin ${ }^{6}$, \\ Yujun George Zheng ${ }^{2}$ and Yingming Zhao ${ }^{1 \times}$
}

\begin{abstract}
Histone lysine crotonylation is a posttranslational modification with demonstrated functions in transcriptional regulation. Here we report the discovery of a new type of histone posttranslational modification, lysine methacrylation (Kmea), corresponding to a structural isomer of crotonyllysine. We validate the identity of this modification using diverse chemical approaches and further confirm the occurrence of this type of histone mark by pan specific and sitespecific anti-methacryllysine antibodies. In total, we identify 27 Kmea modified histone sites in HeLa cells using affinity enrichment with a pan Kmea antibody and mass spectrometry. Subsequent biochemical studies show that histone Kmea is a dynamic mark, which is controlled by HAT1 as a methacryltransferase and SIRT2 as a de-methacrylase. Altogether, these investigations uncover a new type of enzyme-catalyzed histone modification and suggest that methacrylyl-CoA generating metabolism is part of a growing number of epigenome-associated metabolic pathways.
\end{abstract}

\section{Introduction}

The covalent binding of chemical groups from reactive intermediate metabolites to form protein posttranslational modifications (PTMs) has emerged as an important mechanism for regulating cellular processes ${ }^{1,2}$. Histone proteins carry a diverse range of PTMs, which are also known as histone marks, originating from a variety of metabolic pathways ${ }^{3,4}$. The formation of PTMs can occur through either spontaneous chemical reactions or enzymatic reactions ${ }^{5,6}$. Highly energetic metabolites, such as acyl CoAs or S-Adenosyl methionine (SAM), are typical cofactors for enzyme-catalyzed PTM reactions?

Correspondence: Yingming Zhao (yingming.zhao@uchicago.edu)

${ }^{1}$ Ben May Department for Cancer Research, The University of Chicago, Chicago, IL, USA

${ }^{2}$ Department of Pharmaceutical and Biomedical Sciences, University of Georgia, Athens, GA, USA

Full list of author information is available at the end of the article
One of the most studied types of histone marks is lysine acetylation, which is derived from the metabolite acetyl-CoA. However, acetyl-CoA is not the only acyl-CoA capable of forming histone marks. An increasing number of new types of histone marks derived from a variety of acyl-CoA species have been discovered in recent years ${ }^{4,8,9}$. One such example is lysine crotonylation, an enzymatically regulated epigenetic modification associated with active gene expression ${ }^{10,11}$. Since the initial report of its discovery, both crotonyltransferases and de-crotonylases have been identified ${ }^{10-16}$. It has also been shown that some protein modules recognize and bind with better affinity to histone crotonyllysine marks than their corresponding histone acetyllysine marks ${ }^{17-20}$. Diverse studies indicate that histone lysine crotonylation is involved in the transcriptional regulation ${ }^{10,11,14,15,21,22}$. Although multitudes of acyl-CoA metabolite species are involved in cell metabolism, to what extent these other acylCoA metabolites are used in the generation of enzymatically regulated histone modifications remains poorly understood.

\section{(c) The Author(s) 2021}

\footnotetext{
(c) Open Access This article is licensed under a Creative Commons Attribution 4.0 International License, which permits use, sharing, adaptation, distribution and reproduction cc) in any medium or format, as long as you give appropriate credit to the original author(s) and the source, provide a link to the Creative Commons license, and indicate if changes were made. The images or other third party material in this article are included in the article's Creative Commons license, unless indicated otherwise in a credit line to the material. If material is not included in the article's Creative Commons license and your intended use is not permitted by statutory regulation or exceeds the permitted use, you will need to obtain permission directly from the copyright holder. To view a copy of this license, visit http://creativecommons.org/licenses/by/4.0/.
} 
Mounting evidence suggests that previously classified acetyltransferases and deacetylases also regulate non-acetyl acyl modifications. Indeed, some enzymes appear to be more active for the recently identified lysine acylations. For instance, we previously found that SIRT5 specifically targets the negatively charged lysine acylations ${ }^{23,24}$, a finding which is consistent with the work of others ${ }^{25}$. In other cases, enzymes that regulate lysine acetylation also have promiscuous activity for non-acetyl acylations. For example, p300 is an acyltransferase that is capable of utilizing a variety of acyl-CoA substrates ${ }^{26}$. Notably, a proteomics study shows that p300 has unique sets of protein substrates for protein lysine acetylation and lysine 2-hydroxyisobutyrlation, suggesting this acyltransferase exhibits acylation-dependent substrate selectivity ${ }^{27}$. Furthermore, p300 regulates glycolysis through lysine 2-hydroxyisobutyrlation of glycolytic enzymes rather than acetylation of these enzymes ${ }^{27}$. As such, understanding the role of previously classified acetyltransferases and deacetylases in regulating lysine acylations will help us to have a more thorough understanding of their roles in cellular regulations.
Here we report the identification of a new type of histone posttranslational modification, methacryllysine (Kmea). Kmea is a structural isomer of crotonyllysine (Kcr). We validated the identity of Kmea as being separate from Kcr using HPLC and MS/MS analysis of synthetic peptides and ozonolysis reactions. Furthermore, we confirmed that treatment of cells with methacrylate led to direct incorporation of the metabolite into this modification using isotopic labeling. In total, we identified 27 Kmea modified histone sites in HeLa cells using affinity enrichment with a pan Kmea antibody and mass spectrometry. We also found that HAT1 catalyzes the addition of the Kmea on histone $\mathrm{H} 4$ peptide in vitro and ex vivo. We also found that the class III deacetylases SIRT1 and SIRT2 catalyze the removal of Kmea. In summary, we provide the first evidence of Kmea as a new type of posttranslational modification and identify enzymes involved in its addition and removal. In this context, we also demonstrate the ability of HAT1 to catalyze histone lysine methacrylation, reclassifying this enzyme among the growing family of acyltransferase.
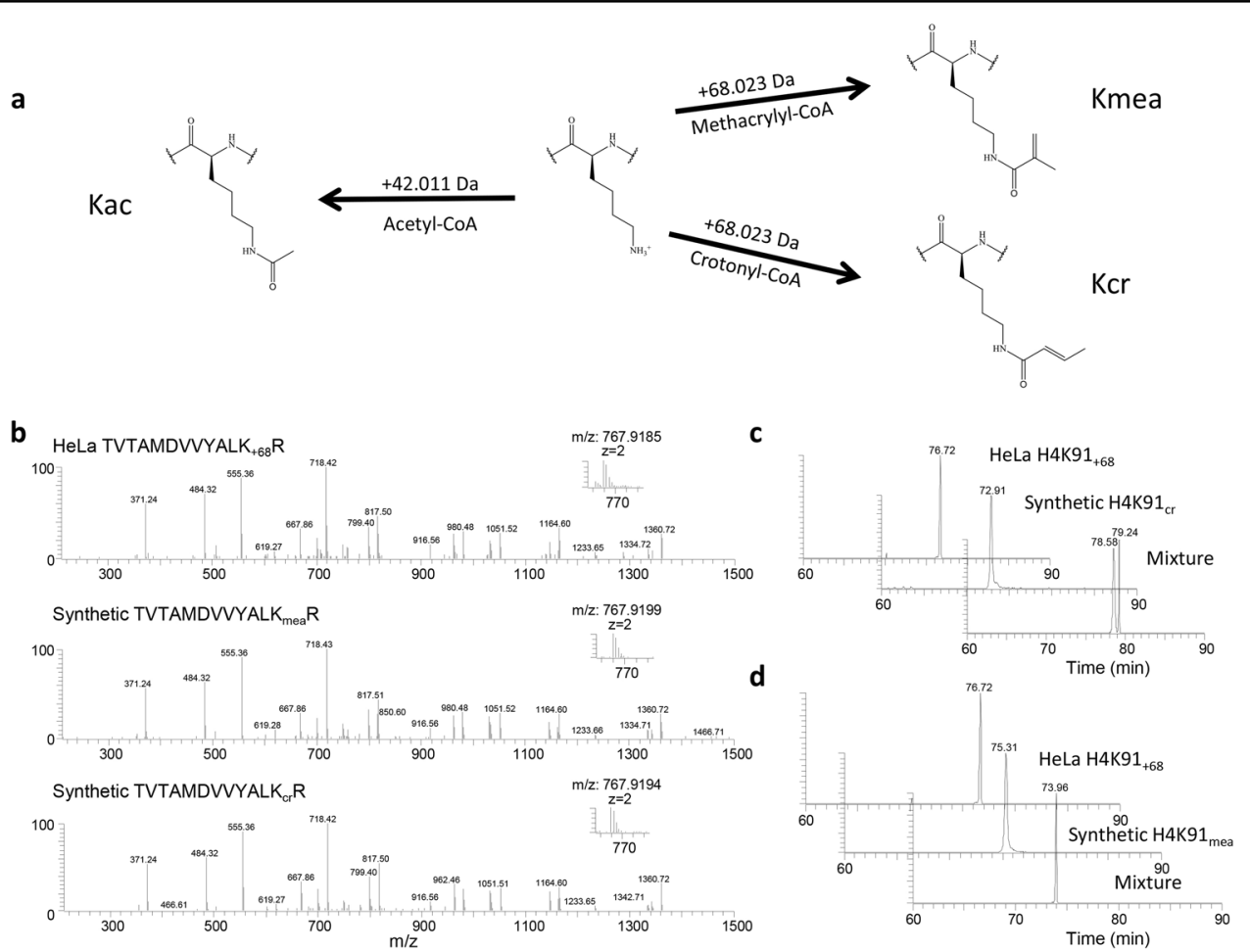

Fig. 1 Identification and verification of lysine methacrylation (Kmea). a Lysine (center) is capable of being modified with multiple different PTMs depending on which acyl-CoA is used in the enzymatic reaction. The appropriate acyl-CoAs as well as the associated mass shift added to a lysine residue is indicated for acetyllysine (left), methacryllysine (Kmea, upper right), and crotonyllysine (Kcr, lower right). b MS/MS spectra of an exemplary HeLa histone peptide (top), synthetic H4K91 ma peptide (middle), and synthetic H4K91cr peptide (bottom). c Extraction ion chromatograms of HeLa cells-derived histone peptide (TVTAMDWYALK ${ }_{+68} \mathrm{R}$ ) (top), synthetic H4K91 cr peptide (middle), and a mixture of the two peptides (bottom). $\mathbf{d}$ Extraction ion chromatograms of HeLa cells-derived histone peptide (TVAMDWYALK +68 R) (top), synthetic H4K91mea peptide (middle), and a mixture of the both peptides (bottom). 


\section{Results}

Discovery and validation of methacryllysine (Kmea)

Based on the ability of various acyl-CoA species to mediate the corresponding lysine acylations, we hypothesized that the endogenous metabolite methacrylylCoA would also mediate the formation of methacryllysine (Kmea) (Fig. 1a). Kmea is a structural isomer of crotonyllysine (Kcr), a modification that we previously discovered $^{11}$. To narrow our search for potential Kmea sites, we focused on those histone lysine sites with a mass shift of $+68.023 \mathrm{Da}$ in HeLa cells that were not labeled by isotopic crotonate in our previous work ${ }^{11}$. This provided us with multiple candidates for which we generated synthetic peptides.

We extracted histones from HeLa cells by acid extraction method and then subjected the samples to tryptic digestion. We analyzed these samples using HPLC/MS/ MS. We compared the fragmentation patterns for histones with $+68.023 \mathrm{Da}$ mass shifts on histone $\mathrm{H} 4$ lysine 91 (H4K91) from HeLa histones to synthetic peptides with either the Kcr or Kmea modifications (Fig. 1b). As an example, the MS/MS pattern is shown for an $\mathrm{H} 4$ peptide identified by HPLC/MS/MS analysis of tryptic peptides derived from HeLa core histones with the peptide sequence TVTAMDVVYALK ${ }_{+68} \mathrm{R}$ (Fig. 1b, top). This ex vivo derived peptide has a nearly identical MS/MS pattern as its corresponding synthetic Kcr and Kmea peptides (Fig. 1b, middle and bottom).
To confirm the identity of the peptide from HeLa histones, we performed co-elution experiments. In co-elution, it is known that any peptides that can be separated by chromatography are confirmed to have distinct chemical structures. We found that the synthetic H4K91cr peptide did not co-elute with the H4K91 + 68.023 peptide derived from HeLa cells (Fig. 1c), confirming that the cellderived peptide was not modified with Kcr. In contrast, we found that the H4K91 + 68.023 Da peptide from HeLa cells co-eluted with the synthetic H4K91mea peptide (Fig. 1d), supporting its identification as a Kmea peptide. We similarly validated H4K31mea using the same approach (Supplementary Fig. S1).

The co-elution experiments could not unambiguously validate two peptides, an $\mathrm{H} 2 \mathrm{~A}$ peptide (NDEELNK ${ }_{+68} \mathrm{LLGK}$

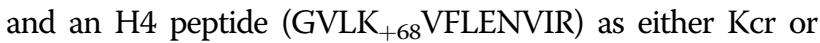
Kmea modification (Supplementary Fig. S2), because the ex vivo-derived peptides co-eluted with their corresponding $\mathrm{Kcr}$ and Kmea peptides. To differentiate the two modifications, we took advantage of the unique double bond in either Kcr or Kmea, and ozonolysis chemistry. In an ozonolysis reaction, ozone cleaves molecules at unsaturated bonds. Structural differences between Kmea and Kcr modifications lead to products with different masses resulting from the reaction (Fig. 2a, b). Ozonolysis of a Kcr-modified peptide generates its corresponding pyruvoyllysine-modified peptide that has a mass shift of $+70.005 \mathrm{Da}$ (Fig. 2a). On the other hand, ozonolysis of a crotonyllysine-modified peptide oxidizes and

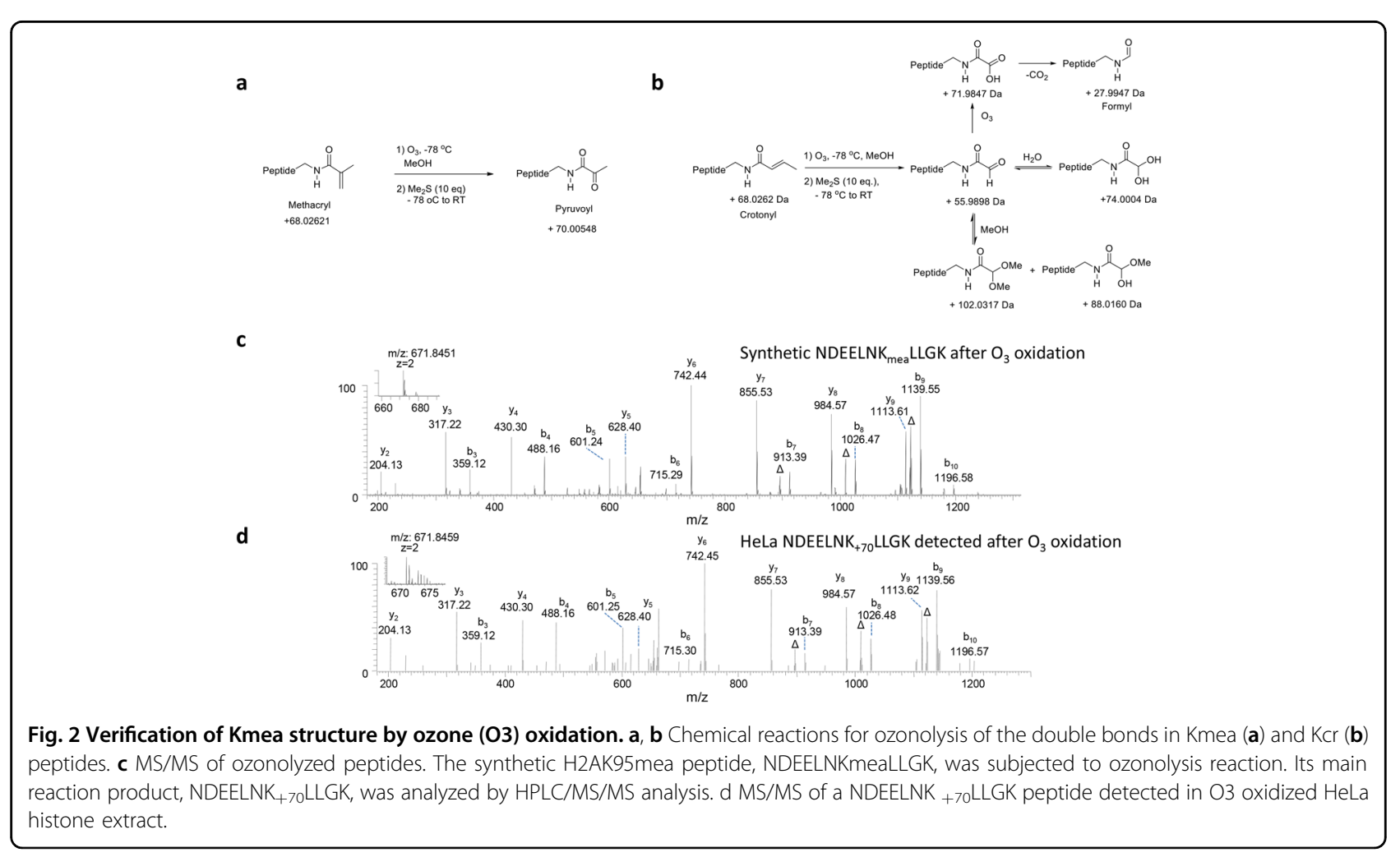




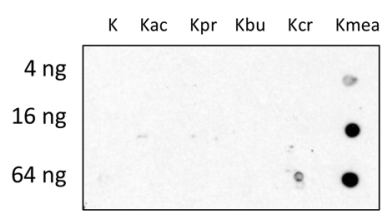

IB: Kmea

b

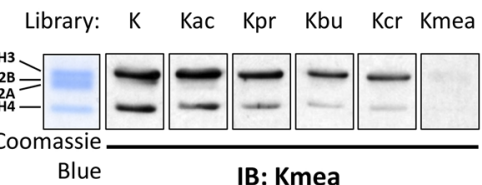

C

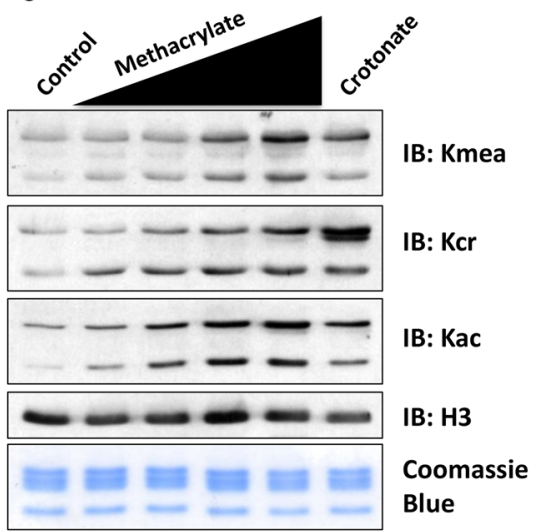

d
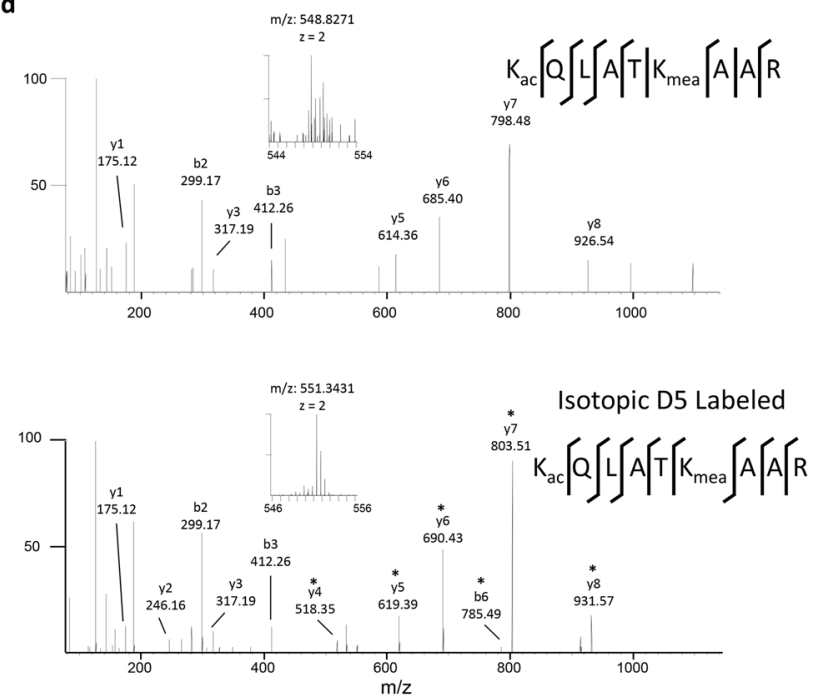

Fig. 3 Methacrylate is a metabolic precursor for Kmea. a Dot blot assay used to assess specificity of a pan anti-Kmea antibody. The Kmea peptide library consists of peptides with the sequence CXXXXXKmeaXXXXX where $C$ is cysteine, $X$ is a mixture of the 19 non-cysteine amino acids, and Kmea is methacryllysine. The control peptides libraries differ in modification status of the central lysine residue where the modifications are abbreviated as follows: K, unmodified lysine; Kac, acetyllysine; Kpr, propionyllysine; Kbu, butyryllysine; and Kcr, crotonyllysine. The amount of peptides spotted in each row of the membrane is indicated. $\mathbf{b}$ Western blotting was performed using a pan anti-Kmea antibody on acid extracted HeLa histones. The pan antiKmea antibody was pre-incubated with peptide libraries for $4 \mathrm{~h}$ prior to immunoblotting of the western blot membrane. The sequences and abbreviations of the peptide libraries are the same as those indicated for the dot blot in a. c Western blot results for histones extracted from HeLa cells. HeLa cells were treated for $24 \mathrm{~h}$ with 1, 3, 5, or $10 \mathrm{mM}$ sodium methacrylate or $10 \mathrm{mM}$ sodium crotonate. d MS/MS spectra of H3K23mea peptide from HeLa histones following treatment with either methacrylate (top) or $\mathrm{d}-7$ methacrylate (bottom). Asterisks $\left(^{*}\right)$ indicate $b$ and $y$ ions with 5 Da mass shift consistent with incorporation of the isotopic metabolite.

cleaves the double bond in the crotonyl group, leading to the production of multiple possible products (Fig. $2 \mathrm{~b}$ ).

To differentiate the two possibilities, we carried out ozonolysis reaction for the ex vivo-derived peptides with a mass shift of $+68 \mathrm{Da}$ and their synthetic counterparts bearing either Kcr or Kmea modification. We measured the reaction products by HPLC/MS/MS to validate the identity of the posttranslational modification isolated from cells. As expected, ozonolysis of the synthetic H2AK95mea peptide, NDEELNK mea $_{\text {LLGK, resulted in a pyruvoylated product }}$ with a mass shift of $+70 \mathrm{Da}$. Importantly, MS/MS spectra of ozonolytic products from synthetic NDEELNK mea $_{\text {LLGK, }}$ and its corresponding ex vivo-derived peptide, both of which have a mass shift of $+70 \mathrm{Da}$, are nearly identical (Fig. 2c, d). Likewise, we carried out the similar experiment for synthetic H2AK95cr peptide, NDEELNK ${ }_{\mathrm{cr}}$ LLGK. Ozonolysis of the peptides produced multiple products, including two major oxidized peptides with mass shifts of +28 and +72 Da (Supplementary Fig. S3), which correspond to the masses of partially and complete oxidized products of the Kcr-modified peptide (Fig. 2a). In summation, the ex vivo derived H2AK95 $+68 \mathrm{Da}$ peptide generated the same 
ozonolytic product as its corresponding Kmea peptide, but not Kcr peptide. Thus, the mass shift in the HeLa H2AK95 + 68.023 Da modified peptide is caused by Kmea instead of Kcr. Likewise, we validated the identity of H4K59mea by this method (Supplementary Fig. S4). In summary, a comparison between four ex vivo-derived histone peptides with their corresponding synthetic peptides, with or without ozonolysis reaction, identified Kmea as a new type of posttranslational modification on histones.

\section{Validation of Kmea by immunochemistry}

To further validate histone Kmea, we generated a polyclonal pan anti-Kmea antibody. By dot blot analysis, we found that the Kmea antibody had 20-fold or more specific binding activity for a Kmea peptide library than the other acylated peptide libraries we tested (Fig. 3a). Furthermore, this pan anti-Kmea antibody detected Kmea on the acid extracted histones from HeLa cells (Fig. 3b). We performed a competition assay by incubating the pan anti-Kmea antibody in the presence of various peptide libraries. The immunoblot signal was competed away using a synthetic Kmea peptide library to a greater extent than when competition was performed with any other tested synthetic peptide library with unmodified, acetylated (Kac), propionylated $(\mathrm{Kpr})$, butyrylated $(\mathrm{Kbu})$, or crotonylated (Kcr) lysines (Fig. 3b). This experiment confirms that the signal we detected by western blot was due to the presence of antibodies in the polyclonal mixture that are specific for the Kmea peptide library. We similarly generated site- specific anti-H4K5mea and antiH3K18mea antibodies and validated their specificity by dot blot (Supplementary Fig. S5a, b).

\section{Methacrylate is a metabolic precursor for histone $\mathrm{Kmea}$}

Acetate and crotonate can be used by cellular shortchain CoA synthetases for the generation of their corresponding CoAs, the cofactors for lysine acylation reactions. We hypothesized that methacrylyl-CoA would serve as the cofactor for lysine methacrylation. Similar to the effects of acetate and crotonate, we hypothesized that treatment of HeLa cells with sodium methacrylate would induce the generation of methacrylyl-CoA that is in turn used by acyltransferases for the formation of Kmea. Consistent with our hypothesis, we found that increasing doses of sodium methacrylate coincided with increases in histone Kmea signal (Fig. 3c). Furthermore, the effect of equimolar doses of methacrylate and crotonate had the strongest effects on increasing signal on Kmea and Kcr, respectively (Fig. 3c). In response to methacrylate treatment, we found similar effects on H4K5mea and H3K18mea visualized by western blot using the corresponding specific antibodies (Supplementary Fig. S5c).

It is of note that the treatment of cells by sodium methacrylate also induced $\mathrm{H} 3$ and $\mathrm{H} 4$ acetylation and crotonylation to some extent (Fig. 3c and Supplementary Fig. S5c). Since the tested antibodies were highly specific by dot blot analysis, these data suggest that methacrylate may somehow affect the production or availability of acetyl and crotonyl-CoA or that it may interfere with the activity of HDACs that remove the acetyl and crotonyl marks. It is known that certain short chain fatty acids, most notably butyrate, lead to increases in Kac by acting as histone deacetylase inhibitors ${ }^{28}$. Additionally, crotonate has also been reported to inhibit HDACs in vitro ${ }^{21}$.

To confirm that methacrylate was capable of serving as a metabolic precursor for Kmea. We treated HeLa cells with $\mathrm{d} 7$-labeled methacrylate for $24 \mathrm{~h}$ before isolating histones through acid extraction. We then tryptically digested the histones and enriched Kmea sites using the pan anti-Kmea antibody. Using this approach, we detected three sites where the isotopic methacrylate was incorporated into the Kmea modification (Fig. 3d, Supplementary Figs. S6, S7).

These results clearly demonstrate that methacrylate can serve as a metabolic precursor for histone Kmea. Furthermore, these results further validate the existence of Kmea as a unique modification that occurs independently of Kcr.

\section{Mapping histone Kmea sites}

An understanding of the potential roles of Kmea will require that we know the modified lysine residues on histones. To identify other Kmea marks on core histones, we treated cells with sodium methacrylate for $24 \mathrm{~h}$ before harvesting cells and performing acid extraction. The resulting core histones were tryptically digested and enriched by immunoprecipitation with the pan anti-Kmea antibody. We performed HPLC-MS/MS analysis on the enriched sample and then analyzed the results using MASCOT software to search for lysine residues bearing $+68.023 \mathrm{Da}$ additional mass. For spectra with a MASCOT score greater than 20, we further manually evaluated spectral quality and removed low quality hits (Supplementary Fig. S7). Altogether, we identified a total 27 Kmea sites across the core histones from HeLa cells (Fig. 4). The positions of Kcr sites that we identified in our original screen of HeLa cells are shown for comparison ${ }^{11}$. A comparison between histone Kmea and Kcr suggest that more Kmea marks were detected outside $\mathrm{N}$-terminal tails on histone $\mathrm{H} 3, \mathrm{H} 4$ and $\mathrm{H} 2 \mathrm{~B}$. In addition, more $\mathrm{Kcr}$ sites were detected on histone $\mathrm{H} 1$ and $\mathrm{H} 2 \mathrm{~A}$. These results demonstrate the widespread occurrences of histone Kmea and suggest the existence of possible distinct mechanisms directing histone lysine methacrylation and histone lysine crotonylation.

\section{HAT1 is a writer for Kmea}

We hypothesized that previously classified acetyltransferases might be able to catalyze the addition of the 


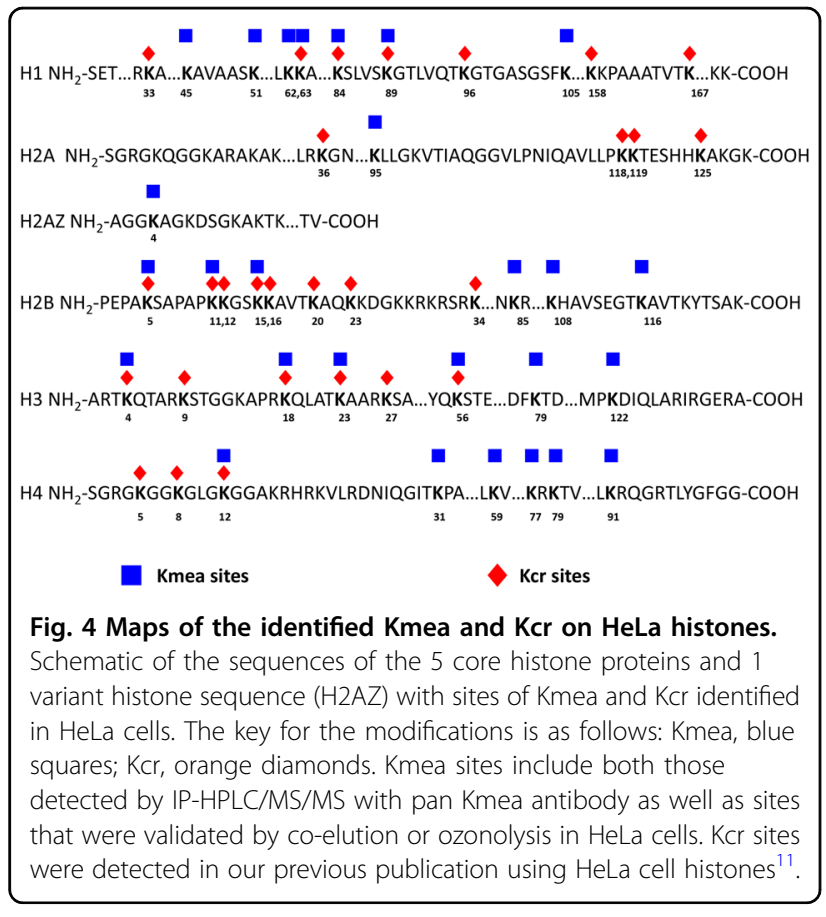

methacryl moiety to lysine. This was based upon the evidence that several of the newly discovered lysine acylations are regulated by enzymes previously classified as acetyltransferases ${ }^{4}$. For example, lysine crotonylation and butyrylation can be catalyzed by $\mathrm{p} 300^{10,26,29}$. We synthesized methacrylyl-CoA and screened for methacryltranferases. There are four major acetyltransferase families in mammals which include: HAT1, GCN5/PCAF, p300/CBP, and MYST. We selected MOF, GCN5, HAT1, and p300, to identify in vitro writers for Kmea, on the basis of being representative members of each of the four major acetyltransferase subfamilies. As expected, the four known acetyltransferases can catalyze in vitro Kac reaction when a synthetic histone $\mathrm{H} 3$ or $\mathrm{H} 4$ peptide was used as a substrate (Supplementary Figs. S8, S9). However, only recombinant HAT1 was able to catalyze the formation of Kmea in the presence of methacrylyl-CoA (Fig. 5a). We further analyzed the kinetics of HAT1 acetyl/acyl-transferase activity using methacrylyl-CoA, acetyl-CoA, and crotonyl-CoA as substrates (Fig. $5 \mathrm{~b}$ ). We found that the $\mathrm{kcat} / \mathrm{Km}$ value for HAT1 with methacrylyl-CoA is 10 -fold lower than the value for acetyl-CoA (Fig. 5c). We were unable to measure the kinetics of HAT1 for crotonyl-CoA beyond the slope of the kinetic curve, which is 0.0057 by linear regression. These data provide the first evidence that the addition of Kmea can be enzymatically catalyzed in vitro.

HAT1 catalyzes lysine acetylation by positioning acetyl$\mathrm{CoA}$ in proximity to lysine residues of histone $\mathrm{H} 4$ in its active site (Fig. 6a). We generated a model of HAT1 in complex with methacrylyl-CoA using the isobutyryl-CoA electron density map from the crystal structure of HAT1isobutyryl-CoA (PDB ID: 6VO5) (Fig. 6b). Similar to the structure with acetyl-CoA, this structure shows the $\varepsilon$ amine of H4K12 is positioned in close proximity to the carbonyl-carbon of the methacrylyl-CoA thioester bond in the active site of HAT1. HAT1 is known to acetylate newly synthesized histone $\mathrm{H} 4$ on lysine residues 5 and $12^{30}$. To test the effects of HAT1 on Kmea in cells, we used our site-specific antibody for H4K5mea that presents high specificity (Supplementary Fig. S5a). It is known that the HAT1-dependent H4K5ac modification is rapidly removed following incorporation of $\mathrm{H} 4$ into chroma$\operatorname{tin}^{31,32}$. We thus hypothesized that we should use newly synthesized histones to analyze Kmea to detect dynamic changes of histone Kmea. To this end, we prepared lysates using RIPA buffer as previously described to acquire samples enriched for newly synthesized and soluble histones $^{33}$. We hypothesized that H4K5mea levels in RIPAsoluble histones would increase with overexpression of HAT1. Consistent with our hypothesis, both H4K5ac and H4K5mea signals increased following overexpression of HAT1-Flag protein in HEK 293 T cells (Fig. 6c). Similarly, knockdown of HAT1 by siRNA but not by control siRNA decreased both H4K5ac and H4K5mea signals (Fig. 6d). Finally, both H4K5mea and H4K5ac levels were much lower in MEF $\mathrm{HAT}^{-/-}$samples relative to $\mathrm{HAT}^{+/+}$ control samples (Fig. 6e). Together, our results indicate that HAT1 catalyzes the transfer of methacryl moiety to histone $\mathrm{H} 4$ in vitro and in mammalian cells.

\section{SIRT2 is an eraser for Kmea in vitro and in cells}

We and others have shown that many of the previously classified lysine deacetylases are able to enzymatically remove other types of lysine acylations in addition to lysine acetylation ${ }^{34}$. Crotonyl moieties on lysine residues can be enzymatically removed by HDAC1-3 and SIRT1$3^{11-13,15}$. A recent screen of HDAC1-11 that included previously discovered and hypothetical substrates bearing lysine acylations revealed that HDAC3 acts as an eraser for lysine methacrylation in vitro ${ }^{35}$. Consistent with this report, we observed that in vitro incubation of HDAC3 with histone extract significantly reduced the Kmea signal detected by western blot (Fig. 7a). Similarly, we observed a large increase in Kmea signal in cells treated for $24 \mathrm{~h}$ with the HDAC class I-II inhibitors butyrate and trichostatin A (Fig. 7b).

Unlike HDAC 1-11, the sirtuin family of enzymes has not been studied for the removal of methacryl from lysine residues. We screened recombinant SIRT1-7 for their ability to enzymatically remove methacryl moiety from synthetic H3K18mea peptides. We found that SIRT1 and SIRT2 had the strongest methacryllysine eraser activity in vitro (Fig. 7c). As a control, we used a peptide bearing H3K18ac, which was efficiently deacetylated by SIRT1-3 

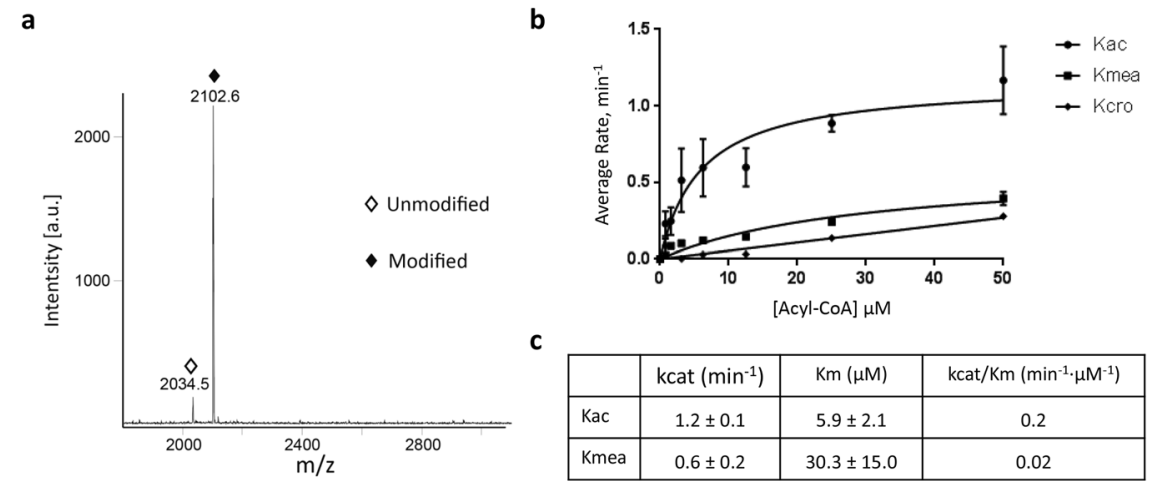

Fig. 5 HAT1 catalyzes Kmea addition in vitro. a Synthetic peptides consisting of the first 20 amino acid residues of the H4 histone, H4 (1-20), were incubated with methacrylyl-CoA and recombinant HAT1 in vitro. MALDI-TOF analysis detected unmodified (open diamond) and methacrylated (solid diamond) peptides. b HAT1 was incubated with acetyl-CoA, methacrylyl- CoA, or crotonyl-CoA at varied concentrations and H4 (1-20) peptide substrates for $15 \mathrm{~min}$, respectively. The enzymatic reaction was quantified using 7-diethylamino-3-(4'-maleimidylphenyl)-4-methylcoumarin (CPM) assay. c The reaction rate-acyl-CoA concentration was plotted with the Michaelis-Menten equation to get the kinetic constants Km and kcat for acetyl-CoA and methacrylyl-CoA substrates, respectively. The kcat/Km values were used to evaluate lysine acylation efficiency.

(Fig. 7d). We confirmed that the effects of SIRT1 and SIRT2 were due to their enzymatic activity as removal of the essential cofactor NAD + from the buffer abolished their ability to remove the methacryl moiety from peptide (Fig. 7e). Similar to our results using synthetic peptides, incubation of recombinant SIRT1 and SIRT2 enzymes with histone extract in vitro greatly reduced the Kmea western blot signal (Fig. 7f). These experiments confirm that SIRT1 and SIRT2 possess the ability to catalytically remove the methacryl moiety from lysines in vitro.

The sirtuin family of deacylases are reported to work on specific histone marks ${ }^{36}$. One of the SIRT2 substrates is H3K18ac, which has been reported to be regulated by the translocation of SIRT2 to the nucleus under certain conditions $^{37}$. We hypothesized that we could also promote H3K18 deacylation following overexpression of SIRT2-Flag in HEK $293 \mathrm{~T}$ cells. We used a highly specific anti-H3K18mea antibody to test our hypothesis (Supplementary Fig. S5b). Consistent with our hypothesis, overexpression of SIRT2-Flag was associated with decreases in the H3K18ac, H3K18cr, and H3K18mea western blot signals relative to the empty vector control (Fig. $7 \mathrm{~g}$ ). In summary, these investigations identify SIRT2 as an enzyme capable of catalyzing the removal of H3K18mea both in vitro and in cells.

\section{Discussion}

The landscape of histone posttranslational modifications has continued to expand in recent years. A particularly notable example is $\mathrm{Kcr}$, an epigenetic modification that is associated with active transcription ${ }^{10,11}$. Kcr is associated with active gene expression during mouse spermatogenesis ${ }^{11,22}$. Similarly, Kcr is also associated with the de-novo activation of genes in RAW 264.7 macrophages following LPS stimulation ${ }^{10}$. Depletion of gut microbiota affects histone $\mathrm{Kcr}$ in the colon ${ }^{21}$. Kcr is also found widely on non-histone proteins, including ribosomal and myofilament proteins in zebrafish embryos $^{38}$. Importantly, writers, readers, and erasers were identified that regulate histone $\mathrm{Kcr}^{4}$. MOF, p300, GCN5, and Esa1 are reported writers for Kcr on histones ${ }^{10,14,39}$. YEATs and PHD domain containing proteins have been identified as readers for $\mathrm{Kcr}$ on histones ${ }^{17-20,40}$. HDAC 1-3 and SIRT 1-3 are the erasers for $\mathrm{Kcr}^{11-13,15}$. Altogether, these data suggest that histone crotonylation is a crucial enzymatically regulated epigenetic modification. However, $\mathrm{Kcr}$ is not the only histone lysine acylation with functions in epigenetic signaling discovered in recent years. As another example, lysine succinylation (Ksucc) occurs on histones and is also associated with transcriptional regulation ${ }^{41-43}$.

Here we report the discovery of Kmea, a structural isomer of Kcr. Certain evidence presented here suggests that Kcr and Kmea could be connected to different regulatory circuits. For example, crotonyl-CoA and methacrylyl-CoA are derived from distinct metabolic pathways. Crotonyl-CoA is an intermediate product of $\beta$-oxidation of fatty acids as well as the catabolism of lysine and tryptophan ${ }^{44}$. In contrast, methacrylyl-CoA is an intermediate product in the mitochondrial catabolism of valine ${ }^{45}$. These differences imply that the accumulation and the regulation of cellular histone/protein $\mathrm{Kcr}$ and Kmea levels likely occur through distinct upstream metabolic pathways. An important unsolved issue concerning not only $\mathrm{Kcr}$ and Kmea, but also various histone acylations, is whether different metabolic pathways leading to generation of the corresponding $\mathrm{CoA}$ derivatives, would also ensure different gene regulatory functions. A noticeable difference between histone 


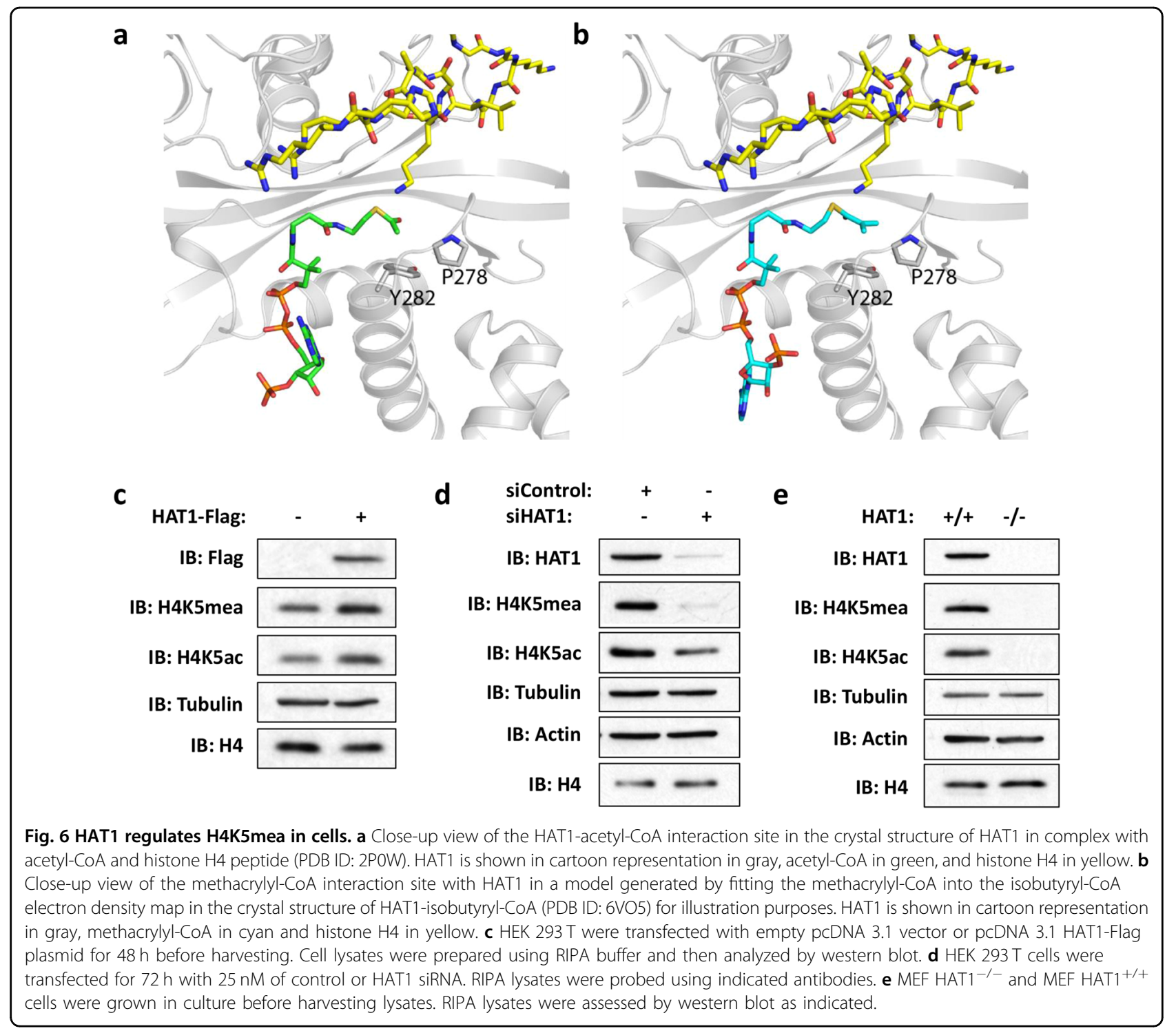

acetylation and acylation is their ability to modulate the binding of bromodomains, especially, the members of BET family to chromatin ${ }^{29}$. Histone methacrylation very likely belongs to the category of short chain histone acylations that could, along with the other acylations, create a barrier against bromodomain factor binding to chromatin. A published work on the role of histone butyrylation showed that the important feature of the highly active gene is not acetylation or butyrylation alone, but is the alternative and dynamic histone acetylation-butyrylation, which is the true signature of active transcription ${ }^{29}$. Histone methacrylation increases therefore the arsenal of chromatin regulatory circuits linking histone acylation to increasing numbers of metabolic pathways. Therefore, this new finding suggests that chromatin could be maintained in an active state depending on a larger number of metabolic pathways than previously anticipated.
The identification of enzymatic writers is essential for deciphering functional relevance of a new type of histone mark and signaling through lysine acylation. For example, identification of the first acetyltransferases represented a milestone for studying signaling pathways involving histone Kac marks ${ }^{30,46,47}$. The transcriptional activator p300 uses not only acetyl-CoA but also the newly discovered acyl-CoAs to modify histones and activate transcription in vitro ${ }^{9,10,27,29}$. In this work, we identify HAT1 as a writer for Kmea. The functional roles of HAT1 remain an area of active study. Recent evidence suggests that HAT1 regulates cellular metabolism. Mice that are heterozygous for HAT1 expression have defects in their mitochondria and present early aging phenotypes ${ }^{48}$. Another study found that HAT1 phosphorylation by AMPK promoted mitochondrial biogenesis ${ }^{49}$. Indeed, the HAT1-mediated acetylation of histones has been proposed to act as a 


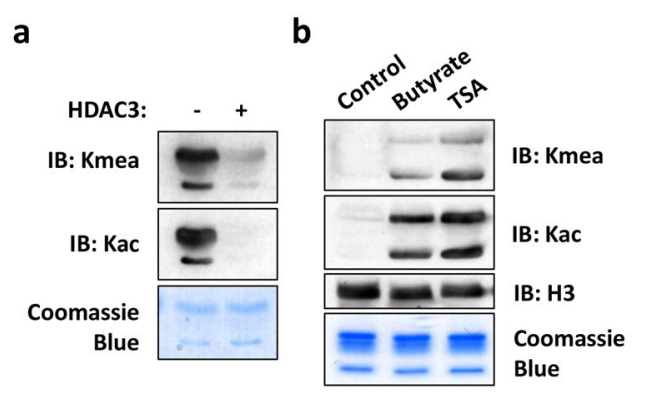

e

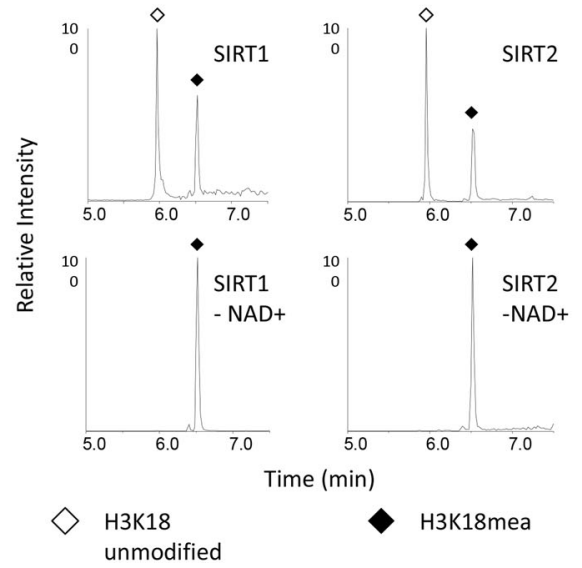

C

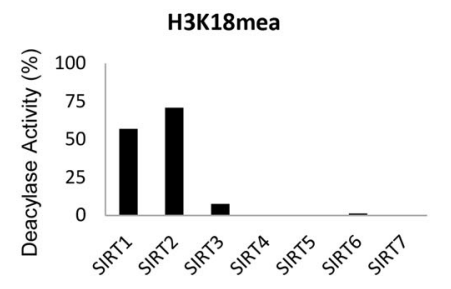

d H3K18ac

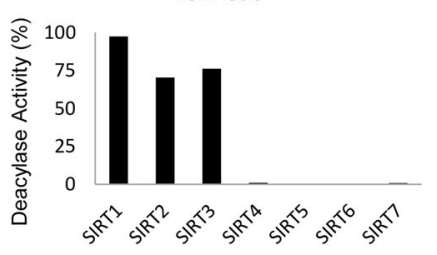

f

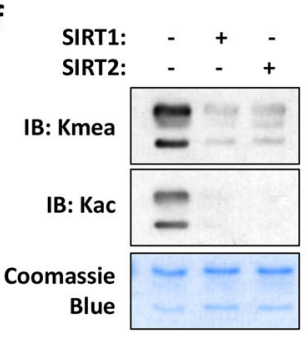

g

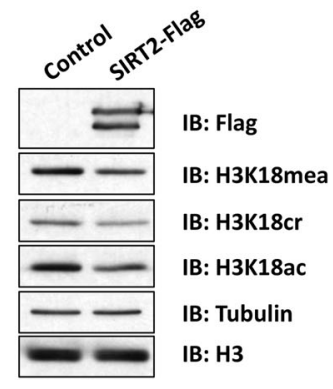

Fig. 7 SIRT1 and SIRT2 remove methacryl from Kmea. a Acid extracted HeLa histones were incubated with or without recombinant HDAC3 for $12 \mathrm{~h}$ at $37^{\circ} \mathrm{C}$. Samples were then analyzed by western blot. b HEK $293 \mathrm{~T}$ cells were treated for $24 \mathrm{~h}$ with either $10 \mathrm{mM}$ sodium butyrate or $1 \mu \mathrm{M}$ TSA. The core histones were prepared by acid extraction method and then subjected to western blot analysis. $\mathbf{c}$, $\mathbf{d}$ Quantitation of deacylase activity of SIRT 1-7 for in vitro screen using either H3K18mea peptide (c) or H3K18ac peptide (d) is shown. The deacylase activity percentage was calculated by dividing the area of the H3K18 unmodified chromatogram peak over the sum of the H3K18 unmodified and modified chromatogram peaks. $\mathbf{e}$ H3K18mea synthetic peptides were incubated with SIRT1 or SIRT2 in presence of reaction buffer with or without its cofactor NAD + . Chromatograms of each sample condition are shown. Open diamonds indicate the H3K18 unmodified peptide peaks. Filled diamonds indicate the H3K18mea peptide peaks. $f$ Acid-extracted HeLa histones were incubated with or without recombinant SIRT1 or SIRT2 for $12 \mathrm{~h}$ at $37^{\circ} \mathrm{C}$. Samples were then analyzed by western blot. $\mathbf{g}$ HEK 293 T cells were transfected with either control empty pcDNA 3.1 vector or pcDNA 3.1 SIRT2-Flag. Whole cell lysates were prepared $48 \mathrm{~h}$ post-transfection and then subjected to western blot analysis with the indicated antibodies.

nutrient sensor coupling the state of cellular metabolism to signals for cell division ${ }^{33}$. We speculate that the ability of HAT1 to use alternative acyl-CoAs like methacrylylCoA may provide additional ways for this enzyme to sense and respond to the state of cellular metabolism. This possibility is reminiscent of our previous finding showing that p300 uses different acyl-CoAs for the regulation of distinct pathways ${ }^{27}$. As such, the discovery of Kmea may provide new insight into deciphering the functions of HAT1 in future studies.

Inherited mutations in the ECHS1 and $\mathrm{HIBCH}$ enzymes of the valine catabolic pathway lead to the development of Leigh syndrome, a neurological disorder characterized by mitochondrial defects ${ }^{50-52}$. Methacrylyl-CoA accumulates in patients with these mutations and has been hypothesized to act as a causal factor in the disease through its electrophilic capacity to alkylate cysteines $^{50}$. The discovery of Kmea raises a potential alternative mechanism for pathological effects of methacrylyl-CoA accumulation. In other in-born-errors of metabolism and physiological changes (e.g., diabetes and hypoxia), elevated levels of acyl-CoAs, such as butyryl-CoA, $\beta$-hydroxybutyryl-CoA, and lactyl-CoA, correlate with higher levels of lysine acylations ${ }^{9,53-55}$. An overabundance of certain lysine acylations is reported to have negative effects on ATP synthase activity, albeit to a relatively small degree ${ }^{56}$. Future studies are needed to determine the targets of Kmea modifications on non-histone proteins as well as their impact on chromatin-independent function.

Both spontaneous lysine acylation and enzymecatalyzed lysine acylation reactions can occur. Extensive literature on the studies of epigenetic function of histone lysine acetylation and its regulation by acetyltransferases, e.g., p300, argue strongly that enzyme catalyzed histone acetylation is the driving force for histone acetylation. It was also reported that a regulatory enzyme is critical for 
function of histone Ksucc and Kcr marks ${ }^{10,41}$. These lines of evidence suggest that in nuclei, enzyme-catalyzed reaction instead of spontaneous reaction is largely responsible for the detected function of histone lysine acylations. Nevertheless, it is also known that acyl-CoAs can react nonenzymatically with the lysine's amine group. The reaction rate is especially higher in the inner mitochondrial matrix where the $\mathrm{pH}$ is higher ${ }^{57}$. Thus, it is highly likely that spontaneous Kmea reactions happen in mitochondria.

While methacrylyl-CoA can be produced in mitochondria through valine catabolism, how methacrylyl-CoA accumulates in the nucleus is another subject that requires further study. Series of investigations have suggested that acetyl-CoA often needs to be produced within the nucleus to be incorporated into nuclear histones ${ }^{58}$. Similarly, nuclear $\alpha-K G D H$ complexes have been shown to provide succinyl-CoA for histone Ksucc ${ }^{41}$. We previously reported that knockdown of the nuclear and cytoplasmic enzyme ACSS2 is associated with depletion of histone $\mathrm{Kcr}^{4}$. In addition, the nuclear pools of crotonylCoA can be further metabolized into $\beta$ - hydroxybutyrylCoA by nuclear CDYL $^{22}$. Whether similar enzymes regulate nuclear methacrylyl- CoA pools is still to be determined. Identification of Kmea and its regulatory elements open a new window to study cross talk between metabolism and epigenetic regulations.

\section{Materials and methods Reagents}

We developed the pan anti-Kmea, anti-H3K18mea, and anti-H4K5mea antibodies in collaboration with PTM Bio Inc. (Chicago, IL). We obtained pan anti-Kcr (PTM-501) and pan anti-Kac (PTM-101) antibodies from PTM Bio Inc. (Chicago, IL). The anti-tubulin (ab6160), anti- H4 (ab31830) and anti-H3 antibody (ab12079) were obtained from Abcam (Cambridge, MA). Anti-Flag (F7425) was obtained from Sigma-Aldrich (St. Louis, MO). We obtained anti-H4K5ac antibody (39700) from Active Motif (Carlsbad, CA). The anti-actin antibody (4967 S) was from Cell Signaling Technologies (Danvers, MA). Methacrylic acid and crotonic acid were obtained from Sigma-Aldrich (St. Louis, MO). The d7-methacrylic acid was obtained from CDN Isotopes (Pointe-Claire, Quebec, Canada). Pooled siRNA for control (D-001810-10-05) and HAT1 (L- 011490-00-0005) were obtained from Horizon Discovery (Waterbeach, United Kingdom). Sequencing grade modified trypsin was obtained from Promega (Madison, WI). Chemicals used in buffers were obtained from SigmaAldrich (St. Louis, MO) unless otherwise noted.

\section{Cell culture}

HeLa and HEK 293 T cells were obtained from ATCC and not validated further. MEF HAT1 wild type and knockout cells were prepared as previously published ${ }^{31}$. Cells were grown in high glucose DMEM (Thermo Fisher Scientific Inc., Waltham, MA) with $10 \% \mathrm{FBS}$ at $37^{\circ} \mathrm{C}$ in $5 \% \mathrm{CO}_{2}$.

\section{Methacrylate and crotonate treatment}

The salt forms of methacrylic acid and crotonic acid were prepared by raising $\mathrm{pH}$ to 7.0-7.3 using $\mathrm{NaOH}$. $\mathrm{HeLa}$ cells were treated crotonate after reaching approximately $50 \%$ confluency. Cells were harvested for histone extraction at $24 \mathrm{~h}$ post treatment. HeLa cells treated with $20 \mathrm{mM} \mathrm{d7-methacrylic} \mathrm{acid} \mathrm{(CDN} \mathrm{Isotopes,}$ Pointe-Claire, Quebec, Canada) were prepared in the same way.

\section{Plasmid transfection}

HEK $293 \mathrm{~T}$ cells were grown to approximately $80 \%$ confluence before transfecting with $2 \mu \mathrm{g}$ of plasmid DNA using Lipofectamine 3000 (Thermo Fischer Scientific Inc., Waltham, MA) according to manufacturer instructions. Culture media was replaced with fresh media at $24 \mathrm{~h}$ posttransfection. Cells were harvested by whole cell lysis at $48 \mathrm{~h}$ post-transfection.

\section{RNAi transfection}

HEK $293 \mathrm{~T}$ cells were transfected with siRNA using Lipofectamine RNAiMAX (Thermo Fisher Scientific Inc., Waltham, MA) for reverse transfection according to manufacturer instructions. Briefly, we added $62.5 \mathrm{pmol}$ of either siControl (Horizon Discovery plc, Waterbeach, United Kingdom, D-001810-10-05) or HAT1 (Horizon Discovery plc, Waterbeach, United Kingdom, L- 01149000-0005) to $500 \mu \mathrm{L}$ Opti-MEM (Thermo Fisher Scientific, Waltham, MA) per well of 6 well plates. Then $10.5 \mu \mathrm{L}$ of RNAiMAX was added to each well. This mixture was incubated at room temperature for $20 \mathrm{~min}$. Then $2 \mathrm{~mL}$ of HEK $293 \mathrm{~T}$ cell suspension in complete media was added to each well. The cells were incubated for $72 \mathrm{~h}$ posttransfection at $37^{\circ} \mathrm{C}$ in $5 \% \mathrm{CO}_{2}$. We replaced the media at the 24 and $48 \mathrm{~h}$ time points post-transfection with fresh complete media. Cells were then harvested and lysates were prepared using RIPA buffer.

\section{Preparation of cell lysates \\ Protein whole-cell lysate}

Cells were harvested upon reaching experimental time points and were greater than $80 \%$ confluent. Cells were washed in PBS once before the addition of lysis buffer (60 mM Tris HCL, pH 6.8; 10\% glycerol; 2\% SDS; and 5\% $\beta$-mercaptoethanol) with the additional inhibitors $1 \mathrm{mM}$ PMSF, $10 \mathrm{mM}$ nicotinamide, and $5 \mathrm{mM}$ sodium butyrate. The adherent cell lysate was scraped from dish and transferred to a microcentrifuge tube. The lysate was then briefly vortexed, boiled for $5 \mathrm{~min}$, and centrifuged at 
greater than $16,000 \times g$ for 5 min before supernatant was transferred to new tube.

\section{RIPA lysate}

For experiments involving HAT1 validation, an alternative lysis approach was used to enrich nascent histones as previously described ${ }^{33}$. Briefly, cells were washed in PBS once before the addition of RIPA buffer (50 mM TrisHCL, pH 7.4; $150 \mathrm{mM} \mathrm{NaCl;} 0.1 \%$ SDS; $0.5 \%$ sodium deoxycholate; $1 \%$ Triton X-100) with the additional inhibitors $1 \mathrm{mM}$ PMSF, $10 \mathrm{mM}$ nicotinamide, and $5 \mathrm{mM}$ sodium butyrate. Adherent cells were scraped in lysis buffer using cell scraper. Lysates were briefly vortexed before centrifuging at greater than $16,000 \times g$ for $10 \mathrm{~min}$ Then supernatant was transferred to a new tube. Laemmli buffer was added to samples that were boiled for $5 \mathrm{~min}$ prior to use in SDS-PAGE.

\section{Histone extraction}

Acid extraction of histones was performed according to modified version of a published protocol ${ }^{59}$. Briefly, cells were harvested in $10-\mathrm{cm}$ plates after reaching approximately $90 \%$ confluency. Cells were washed in phosphate buffered saline (PBS) before detaching from plate by cell scraper. Cells were then washed and pelleted in PBS twice at $1000 \times g$ for $5 \mathrm{~min}$ at $4{ }^{\circ} \mathrm{C}$. Cellular plasma membranes were lysed in extraction buffer (10 mM HEPES pH 7.0, $10 \mathrm{mM} \mathrm{KCl}, 1.5 \mathrm{mM} \mathrm{MgCl} 2,0.34 \mathrm{M}$ sucrose, $0.5 \% \mathrm{NP}-40$, $5 \mathrm{mM}$ sodium butyrate, $10 \mathrm{mM}$ nicotinamide) for $10 \mathrm{~min}$ with gentle agitation at $4{ }^{\circ} \mathrm{C}$. Nuclei were then pelleted at $2000 \times g$ at $4{ }^{\circ} \mathrm{C}$ for $10 \mathrm{~min}$ and supernatant was discarded. Cells were resuspended in extraction buffer without NP40 , cell nuclei were pelleted at $2000 \times g$ at $4{ }^{\circ} \mathrm{C}$ for $5 \mathrm{~min}$. Nuclear pellets were then lysed in a nuclear lysis buffer (3 mM EDTA, $0.2 \mathrm{mM}$ EGTA, $5 \mathrm{mM}$ sodium butyrate, $10 \mathrm{mM}$ nicotinamide) for $30 \mathrm{~min}$ with gentle agitation at $4{ }^{\circ} \mathrm{C}$. Chromatin was pelleted at $6500 \times g$ for 5 min at $4{ }^{\circ} \mathrm{C}$ and then resuspended in $0.4 \mathrm{~N} \mathrm{H} 2 \mathrm{SO} 4$. Chromatin suspension in acid was incubated overnight at $4{ }^{\circ} \mathrm{C}$ with gentle agitation. After centrifuging at $16,000 \times g$ for $10 \mathrm{~min}$, acid soluble supernatant was collected and used in trichlorooacetic acid (TCA) precipitation. Following TCA precipitation, histones were pelleted and washed three times in cold acetone. Histones were finally resuspended in deionized water.

\section{Trypsin digestion}

Isolated histones were in-solution digested using sequencing grade modified trypsin at a ratio of 50:1, respectively. Buffer was adjusted to $\mathrm{pH} 8$ using ammonium bicarbonate. Samples were incubated at $37^{\circ} \mathrm{C}$ overnight. Following incubation, samples were boiled for $1 \mathrm{~min}$ to inactivate trypsin.

\section{Peptide enrichment by immunoprecipitation and identification by HPLC/MS/MS}

We began by conjugating pan anti-Kmea antibodies to nProtein A Sepharose beads (GE Healthcare Bio-Sciences Corp., Piscataway, NJ). The bead conjugated antibodies were then incubated in the presence of tryptically digested peptides at $4{ }^{\circ} \mathrm{C}$ with gentle agitation. We washed the beads with NETN buffer $(50 \mathrm{mM}$ Tris-Cl pH 8.0, $1 \mathrm{mM}$ EDTA, $100 \mathrm{mM} \mathrm{NaCl}, 0.5 \% \mathrm{NP}-40$ ) three times. This was followed by two washes in ETN buffer which lacked the $0.5 \%$ NP- 40. This was followed once with deionized water. We then eluted peptides using $0.1 \%$ trifluoroacetic acid. The eluted peptides were then dried in a SpeedVac (Thermo Fisher Scientific Inc.).

Dried peptides samples were dissolved in HPLC Buffer A $(0.1 \%$ formic acid in water, $\mathrm{v} / \mathrm{v})$ and loaded into a homemade capillary column $(10-\mathrm{cm}$ length $\times 75-\mathrm{mm}$ ID, $3-\mu \mathrm{m}$ particle size, Dr. Maisch GmbH, Ammerbuch, Germany) attached to an EASY-nLC 1000 system (Thermo Fisher Scientific Inc., Waltham, MA). We separated and eluted peptides along a gradient of 2 to $90 \%$ HPLC Buffer B $(0.1 \%$ formic acid in acetonitrile, $v / v$ ) in HPLC Buffer $A$ at a flow rate of $200 \mathrm{~nL} \mathrm{~min}^{-1}$ over $60 \mathrm{~min}$. The peptides were ionized and analyzed using a Q-Exactive mass spectrometer (Thermo Fisher Scientific Inc., Waltham, MA).

\section{Validation of methacryllysine peptides using HPLC/MS/MS}

We injected synthetic methacrylated or crotonylated peptides, with or without mixing with tryptically digested histones derived from cultured cells, into nano-HPLC system that is online coupled with a LTQ Orbitrap Velos Mass Spectrometer. The HPLC/MS/MS analysis were carried out as described above.

\section{Dot blot assay}

Synthetic peptides were spotted onto nitrocellulose membrane in the amounts indicated in the figures. Membranes were incubated in blocking buffer ( $3 \%$ bovine serum albumin, $20 \mathrm{mM}$ tris- buffered saline $\mathrm{pH}$ 7.6, 0.1\% Tween-20) for $1 \mathrm{~h}$ at room temperature with gentle agitation. Membranes were incubated in solution of primary antibody diluted in $1 \%$ BSA blocking buffer and incubated for $30 \mathrm{~min}$ at room temperature with gentle agitation. Blots were washed three times in TBST. Then, membranes were incubated in secondary antibody diluted in 1\% BSA in TBST for $30 \mathrm{~min}$ at room temperature with gentle agitation. Blots were washed three times in TBST and then incubated for $1 \mathrm{~min}$ in enhanced chemiluminescence reagent. Film was exposed in dark room to visualize antibody binding.

\section{Western blot and peptide competition assay}

The protein samples of interest were resolved in SDSPAGE and transferred to $0.2 \mu \mathrm{m}$ PVDF membranes. Membranes were incubated in blocking buffer ( $3 \%$ bovine serum 
albumin, $20 \mathrm{mM}$ tris-buffered saline $\mathrm{pH}$ 7.6, 0.1\% Tween-20) for $1 \mathrm{~h}$ at room temperature. Membranes were probed with primary antibody in 1\% BSA blocking buffer overnight at $4{ }^{\circ} \mathrm{C}$ with gentle agitation. Secondary HRP conjugated antibodies were incubated for $1 \mathrm{~h}$ at room temperature. Membranes were washed 3 times for 8 min each in TBST $(20 \mathrm{mM}$ tris-buffered saline $\mathrm{pH}$ 7.6, 0.1\% Tween-20) following both primary and secondary antibody incubations. Film was exposed in dark room after incubating for $1 \mathrm{~min}$ in enhanced chemiluminescence reagent with gentle agitation.

For peptide competition assay, a pan anti-Kmea antibody was incubated in the presence of 500 molar excess of peptide libraries for $4 \mathrm{~h}$ at room temperature with gentle incubation. This solution was used as the primary antibody incubation overnight at $4{ }^{\circ} \mathrm{C}$ with gentle agitation. All other steps are consistent with the western blot protocol as described.

\section{Expression and purification of HAT1}

The expression and purification of human HAT1 (20341) was carried out following the method described in Hong Wu et al. ${ }^{60}$. The pET28a-LIC-HAT1 plasmid (Addgene, plasmid \#25239) was transformed into BL21 (DE3)/RIL competent cells through heat-shock and then spread on plates containing antibiotics kanamycin and chloramphenicol. Protein expression was induced by the addition of IPTG (final concentration: $1.0 \mathrm{mM}$ ) and shaken for $16 \mathrm{~h}$ at $16^{\circ} \mathrm{C}$. The cells were collected and suspended in lysis buffer $(50 \mathrm{mM}$ Na-phosphate ( $\mathrm{pH} 7.4)$, $250 \mathrm{mM} \mathrm{NaCl}, 5 \mathrm{mM}$ imidazole, $5 \%$ glycerol, $2 \mathrm{mM}$ $\beta$-mercaptoethanol, and $1 \mathrm{mM}$ PMSF) then disrupted using the cell disruptor. The supernatant was passed through a column containing Ni-NTA resin equilibrated with column washing buffer ( $20 \mathrm{mM}$ Tris- $\mathrm{HCl}(\mathrm{pH} 8.0)$, $250 \mathrm{mM} \mathrm{NaCl}, 5 \%$ glycerol, $30 \mathrm{mM}$ imidazole, and $1 \mathrm{mM}$ PMSF) and the resin was washed twice with the same column washing buffer. Next, the resin was washed three times with buffer containing a higher concentration of imidazole ( $20 \mathrm{mM}$ Tris- $\mathrm{HCl}$ (pH 8.0), $250 \mathrm{mM} \mathrm{NaCl}, 5 \%$ glycerol, $50 \mathrm{mM}$ imidazole, and $1 \mathrm{mM}$ PMSF). The resin then was eluted with elution buffer $(20 \mathrm{mM}$ Tris- $\mathrm{HCl}(\mathrm{pH}$ 8.0), $250 \mathrm{mM} \mathrm{NaCl}, 5 \%$ glycerol, $500 \mathrm{mM}$ imidazole, and $1 \mathrm{mM}$ PMSF), and dialyzed in the dialysis buffer $(25 \mathrm{mM}$ Tris- $\mathrm{HCl}$ (pH 8.0), $150 \mathrm{mM} \mathrm{NaCl}, 10 \%$ glycerol, $1 \mathrm{mM}$ DTT) at $4{ }^{\circ} \mathrm{C}$ overnight. Thrombin was added to the dialyzed protein containing HAT1 and dialyzed in thrombin cleavage buffer (20 mM Tris- $\mathrm{HCl}$ (pH 8.0), $100 \mathrm{mM} \mathrm{NaCl}$, $2.5 \mathrm{mM} \mathrm{CaCl}_{2}, 5 \%$ glycerol, $1 \mathrm{mM} \mathrm{DTT}$ ) for $20 \mathrm{~h}$ at $4{ }^{\circ} \mathrm{C}$ to remove the His6 $\times$-tag. The resultant protein was concentrated and purified by anion exchange chromatography using the NGC FPLC system. The identification of HAT1 was confirmed using SDS-PAGE. Millipore centrifugal filter and Bradford assay were used to concentrate and determine the protein's concentration, respectively. Lastly, the protein was aliquoted, flash frozen by liquid nitrogen and stored at $-80^{\circ} \mathrm{C}$.

\section{Synthesis of methacrylyl-CoA}

CoA ( $5 \mathrm{mg}, 0.0065 \mathrm{mmol}$ ) was dissolved in $1.5 \mathrm{~mL}$ of $0.5 \mathrm{M} \mathrm{NaHCO} 3(\mathrm{pH} 8.0)$ and cooled down on ice bath. Then methacrylic anhydride $(10.02 \mathrm{mg}, 0.065 \mathrm{mmol})$ in $1 \mathrm{~mL}$ of acetonitrile/acetone $(1: 1 \mathrm{v} / \mathrm{v})$ was added dropwise to the CoA solution. The reaction solution was stirred at $4{ }^{\circ} \mathrm{C}$ overnight, and then quenched by adjusting $\mathrm{pH}$ to 4 with $1 \mathrm{M} \mathrm{HCl}$. The reaction mixture was subjected to RPHPLC purification with gradient $5 \%-45 \%$ acetonitrile over $30 \mathrm{~min}$ at flow rate $5 \mathrm{~mL} / \mathrm{min}$; UV wavelengths were set at 214 and $254 \mathrm{~nm}$ for peak detection. HPLC eluents were $0.05 \%$ TFA in water (solution A) and $0.05 \%$ TFA in acetonitrile (solution $\mathrm{B}$ ). The fractions were collected and lyophilized after flash-freeze with liquid nitrogen. Methacrylyl-CoA was collected as white solid, $3.6 \mathrm{mg}$, yield $72 \%$. $1 \mathrm{H}$ NMR $(400 \mathrm{MHz}, \mathrm{D} 2 \mathrm{O}) \delta 8.54(\mathrm{~s}, 1 \mathrm{H}), 8.32$ $(\mathrm{s}, 1 \mathrm{H}), 6.10(\mathrm{~s}, 1 \mathrm{H}), 5.96(\mathrm{~s}, 1 \mathrm{H}), 5.58(\mathrm{~s}, 1 \mathrm{H}), 4.49(\mathrm{~s}, 1 \mathrm{H})$, $4.16(\mathrm{~s}, 2 \mathrm{H}), 3.91(\mathrm{~s}, 1 \mathrm{H}), 3.76(\mathrm{dd}, \mathrm{J}=9.5,4.4 \mathrm{~Hz}, 1 \mathrm{H})$, $3.50(\mathrm{~d}, \mathrm{~J}=5.0 \mathrm{~Hz}, 1 \mathrm{H}), 3.33(\mathrm{t}, \mathrm{J}=6.3 \mathrm{~Hz}, 2 \mathrm{H}), 3.23(\mathrm{dd}, \mathrm{J}$ $=11.8,5.6 \mathrm{~Hz}, 2 \mathrm{H}), 2.92(\mathrm{t}, \mathrm{J}=6.0 \mathrm{~Hz}, 2 \mathrm{H}), 2.32(\mathrm{t}, \mathrm{J}=$ $6.3 \mathrm{~Hz}, 2 \mathrm{H}), 1.78$ (s, 3H), $0.83(\mathrm{~s}, 3 \mathrm{H}), 0.70(\mathrm{~s}, 3 \mathrm{H})$.

\section{In vitro acetyltransferase assay}

Acetyl-CoA lithium salt (A2181) was purchased from Sigma-Aldrich (St. Louis, MO) and dissolved in water to make the stock solution. The thiol-reactive probe 7-diethylamino-3-(4'-maleimidylphenyl)-4-methylcoumarin (CPM) (Cat\# D346, Thermo Fischer Scientific Inc., Waltham, MA) was dissolved in $100 \%$ DMSO to make the stock solution at $1 \mathrm{mM}$. Both solutions were aliquoted, stored at $-20^{\circ} \mathrm{C}$ and ready to use immediately before experiments. We combined $0.5 \mu \mathrm{M}$ recombinant enzyme, $100 \mu \mathrm{M}$ acetyl-CoA or methacrylyl-CoA, with $50 \mu \mathrm{M}$ histone $\mathrm{H} 3$ or $\mathrm{H} 4$ peptide. Reaction mixtures were incubated at $30^{\circ} \mathrm{C}$ for $2 \mathrm{~h}$. Synthetic histone peptides substrates consisted of the first 20 amino acids of the $\mathrm{N}$-terminal tails of histones $\mathrm{H} 3$ and $\mathrm{H} 4$ with acetylation of the $\mathrm{N}$-terminal peptide amine. The sequences for $\mathrm{H} 3$ (1- 20) and $\mathrm{H} 4$ (120) were Ac-ARTKQTARKSTGGKAPRKQL and AcSGRGKGGKGLGKGGAKRHRK, respectively. Reactions with GCN5 and p300 as enzymes were paired with synthetic H3 (1-20) peptide as substrate. Similarly, reactions with MOF and HAT1 were paired with synthetic H4 (120 ) as substrate. Samples were analyzed by MALDI- TOF MS to identify if peptide substrates were modified in the reactions, respectively.

\section{Steady-state kinetics of HAT1 acetylation and methacrylation}

Varied concentrations of acetyl-CoA (Sigma Aldrich, Cat\# A2181), methacrylyl-CoA and crotonyl-CoA were 
incubated with $0.1 \mu \mathrm{M}$ HAT1 and $200 \mu \mathrm{M}$ of H4 (1-20) peptide (sequence: Ac-SGRGKGGKGLGKGGAKRHRK). The enzymatic reactions were conducted at $30^{\circ} \mathrm{C}$ for 15 min in KAT reaction buffer containing $50 \mathrm{mM}$ HEPES$\mathrm{Na}$ and $0.1 \mathrm{mM}$ EDTA-Na, $\mathrm{pH}$ 8.0. The reactions were quenched by $50 \%$ isopropanol and incubated with the probe 7-diethylamino-3-(4'-maleimidylphenyl)-4-methylcoumarin (abbr. CPM, Thermo Fisher, Cat\# D346) in the darkness for $30 \mathrm{~min}$ at room temperature, producing the fluorescent CPM-SCoA complex. The fluorescence intensities were measured at an excitation of $392 \mathrm{~nm}$ and an emission of $482 \mathrm{~nm}$ with FlexStation ${ }^{\circledR} 3$ microplate reader to obtain reaction rate for each datapoint. Kinetic constants including binding affinity $(\mathrm{Km})$ and catalytic rate (kcat) were determined by fitting the acyl-CoA concentration- rate curve to the Michaelis-Menten equation using GraphPad Prism.

\section{In vitro sirtuin peptide assay}

Recombinant sirtuin proteins were obtained from BPS Biosciences Inc. (San Diego, CA). In vitro sirtuin reactions were performed by combining $0.5 \mu \mathrm{M}$ synthetic peptide with $0.25 \mu \mathrm{M}$ sirtuin in $20 \mathrm{mM}$ Tris-HCL, $\mathrm{pH} 8$ with $1 \mathrm{mM} \mathrm{NAD} \mathrm{+} \mathrm{and} 1 \mathrm{mM}$ DTT in total volume of $50 \mu \mathrm{l}$. Mixtures incubated at $37^{\circ} \mathrm{C}$ for $1 \mathrm{~h}$. Reaction was quenched by adding $50 \mu \mathrm{l}$ of $200 \mathrm{mM} \mathrm{HCl}$ and $320 \mathrm{mM}$ acetic acid in HPLC grade methanol. Samples were dried using SpeedVac. Samples were desalted by ZipTip before being subjected to HPLC/MS/MS analysis. Percent deacetylase activity was measured by dividing the area of the unmodified peptide chromatographic peak over the sum of the area of the unmodified and modified chromatographic peaks.

\section{In vitro HDAC assay}

Recombinant HDAC3, SIRT1, and SIRT2 were all obtained from BPS Biosciences Inc (San Diego, CA). The reaction buffer for the sirtuins was $20 \mathrm{mM}$ Tris-HCL, $\mathrm{pH}$ 8 with $1 \mathrm{mM}$ NAD + and $1 \mathrm{mM}$ DTT. HDAC3 reaction buffer consisted of $25 \mathrm{mM}$ Tris $\mathrm{pH} 8,130 \mathrm{mM} \mathrm{NaCl}$, $3.0 \mathrm{mM} \mathrm{KCl}, 1 \mathrm{mM} \mathrm{MgCl}_{2}$, and 0.1\% PEG8000, pH 8.0. We treated HeLa cells with $20 \mathrm{mM}$ sodium methacrylate for $24 \mathrm{~h}$ prior to performing histone extraction. The recombinant enzyme of interest was mixed with a histone extract at a ratio of $0.2 \mu \mathrm{g}$ enzyme per $2 \mu \mathrm{g}$ of histone extract in the appropriate buffer. Mixtures were incubated at $37^{\circ} \mathrm{C}$ for $12 \mathrm{~h}$. The samples were then analyzed by western blotting.

\section{Acknowledgements}

We thank He Huang, Di Zhang, and Yejing Weng for their technical assistance. This work was supported by the University of Chicago, Nancy and Leonard Florsheim family fund, NIH grants (R01GM135504, R01DK118266,

R01GM062970, RO1AR078555) andNSF1808087. S.Kh. laboratory is supported by a grant from Fondation ARC, PGA1RF2019208471 as well as by ANR
Episperm4 program. Additional supports were from: Plan Cancer (CH7INS15B66, C7H-KIC19N30-IAB and ASC16012CSA), INCa-IReSP (R19051CC) and the 'University Grenoble Alpes' ANR-15-IDEX-02 (SYMER and LIFE). The Structural Genomics Consortium is a registered charity (1097737) that receives funds from AbbVie; Bayer Pharma AG; Boehringer Ingelheim; Canada Foundation for Innovation; Eshelman Institute for Innovation; Genentech, Genome Canada through Ontario Genomics Institute [OGI-196]; EU/EFPIA/ OICR/McGill/KTH/Diamond Innovative Medicines Initiative 2 Joint Undertaking [EUbOPEN grant 875510]; Janssen, Merck \& Co.; Novartis Pharma AG; Pfizer, São Paulo Research Foundation-FAPESP, Takeda and the Wellcome Trust.

\section{Author details}

${ }^{1}$ Ben May Department for Cancer Research, The University of Chicago, Chicago, IL, USA. ${ }^{2}$ Department of Pharmaceutical and Biomedical Sciences, University of Georgia, Athens, GA, USA. ${ }^{3}$ College of Pharmacy, Research Institute of Pharmaceutical Sciences, Kyungpook National University, Daegu, South Korea. ${ }^{4}$ Structural Genomics Consortium, University of Toronto, Toronto, ON, Canada. ${ }^{5}$ Department of Biological Chemistry and Pharmacology, The Ohio State University, Columbus, OH, USA. ${ }^{6}$ CNRS UMR 5309, INSERM, U1209, Université Grenoble Alpes, Institute for Advanced Biosciences, Grenoble, France. ${ }^{7}$ Present address: Shanghai Institute of Materia Medica, Chinese Academy of Sciences, Shanghai, China. ${ }^{8}$ Present address: Department of General Practice, State Key Laboratory of Biotherapy, West China Hospital, Sichuan University, and Collaborative Innovation Center of Biotherapy, Chengdu, China

\section{Author contributions}

Y.Z., K.D. and M.T. conceived and designed the experiments. Y.Z. and K.D. wrote the manuscript. K.D. performed the majority of the experiments. M.T. and L.D. performed co-elution and ozonolysis mass spectrometry experiments. M.H., Z.Z. and Y.G.Z. synthesized methacrylyI-CoA and performed in vitro acetyltransferase assays. S. Kim operated HPLC-MS/MS for histone site identification. J.D. and L.Y. operated HPLC-MS/MS for in vitro sirtuin assays. L.H. performed structural modeling of HAT1. J.G. developed in-house software for identification of PTM sites and performed analysis using this software. P.N. and M.R.P. created and provided MEF HAT1 ${ }^{-1-}$ cells. S.L. and S. Khochbin provided expertise.

\section{Conflict of interest}

Y.Z. is a founder, equity owner, board member, advisor to, and inventor on patents licensed to PTM Bio Inc. and Maponos Therapeutics Inc. The authors declare no competing interests.

\section{Publisher's note}

Springer Nature remains neutral with regard to jurisdictional claims in published maps and institutional affiliations.

Supplementary information The online version contains supplementary material available at https://doi.org/10.1038/s41421-021-00344-4.

Received: 19 April 2021 Accepted: 13 September 2021

Published online: 28 December 2021

\section{References}

1. Diehl, K. L. \& Muir, T. W. Chromatin as a key consumer in the metabolite economy. Nat. Chem. Biol. 16, 620-629 (2020).

2. Lin, H., Su, X. \& He, B. Protein lysine acylation and cysteine succination by intermediates of energy metabolism. ACS Chem. Biol. 7, 947-960 (2012).

3. Huang, H., Sabari, B. R., Garcia, B. A., Allis, C. D. \& Zhao, Y. SnapShot: histone modifications. Cell 159, 458-458.e451 (2014).

4. Sabari, B. R., Zhang, D., Allis, C. D. \& Zhao, Y. Metabolic regulation of gene expression through histone acylations. Nat. Rev. Mol. Cell Biol. 18, 90-101 (2017).

5. Moellering, R. E. \& Cravatt, B. F. Functional lysine modification by an intrinsically reactive primary glycolytic metabolite. Science $\mathbf{3 4 1}$, 549-553 (2013).

6. Zheng, Q., Maksimovic, I., Upad, A. \& David, Y. Non-enzymatic covalent modifications: a new link between metabolism and epigenetics. Protein Cell 11, 401-416 (2020). 
7. Walsh, C. T., Garneau-Tsodikova, S. \& Gatto, G. J. Jr. Protein posttranslational modifications: the chemistry of proteome diversifications. Angew. Chem. Int. Ed. 44, 7342-7372 (2005).

8. Huang, $\mathrm{H}$. et al. Lysine benzoylation is a histone mark regulated by SIRT2. Nat. Commun. 9, 3374 (2018).

9. Zhang, D. et al. Metabolic regulation of gene expression by histone lactylation. Nature 574, 575-580 (2019).

10. Sabari, B. R. et al. Intracellular crotonyl-CoA stimulates transcription through p300- catalyzed histone crotonylation. Mol. Cell 58, 203-215 (2015).

11. Tan, M. et al. Identification of 67 histone marks and histone lysine crotonylation as a new type of histone modification. Cell 146, 1016-1028 (2011).

12. Bao, $X$. et al. Identification of 'erasers' for lysine crotonylated histone marks using a chemical proteomics approach. Elife 3 (2014).

13. Feldman, J. L., Baeza, J. \& Denu, J. M. Activation of the protein deacetylase SIRT6 by long-chain fatty acids and widespread deacylation by mammalian sirtuins. J. Biol. Chem. 288, 31350-31356 (2013).

14. Liu, X. et al. MOF as an evolutionarily conserved histone crotonyltransferase and transcriptional activation by histone acetyltransferase-deficient and crotonyltransferase-competent CBP/p300. Cell Discov. 3, 17016 (2017).

15. Wei, W. et al. Class I histone deacetylases are major histone decrotonylases: evidence for critical and broad function of histone crotonylation in transcription. Cell Res. 27, 898-915 (2017).

16. Yan, K. et al. Deficient histone H3 propionylation by BRPF1-KAT6 complexes in neurodevelopmental disorders and cancer. Sci. Adv. 6, eaax0021 (2020).

17. Andrews, F. H. et al. The Taf14 YEATS domain is a reader of histone crotonylation. Nat. Chem. Biol. 12, 396-398 (2016).

18. Li, Y. et al. Molecular coupling of histone crotonylation and active transcription by AF9 YEATS domain. Mol. Cell 62, 181-193 (2016).

19. Xiong, $X$. et al. Selective recognition of histone crotonylation by double PHD fingers of MOZ and DPF2. Nat. Chem. Biol. 12, 1111-1118 (2016).

20. Zhao, D. et al. YEATS2 is a selective histone crotonylation reader. Cell Res. 26, 629-632 (2016).

21. Fellows, R. et al. Microbiota derived short chain fatty acids promote histone crotonylation in the colon through histone deacetylases. Nat. Commun. 9, 105 (2018). 773.

22. Liu, S. et al. Chromodomain protein CDYL acts as a crotonyl-CoA hydratase to regulate histone crotonylation and spermatogenesis. Mol. Cell 67, 853-866. e855 (2017)

23. Peng, $C$. et al. The first identification of lysine malonylation substrates and its regulatory enzyme. Mol. Cell Proteom. 10, M111.012658 (2011).

24. Tan, $M$. et al. Lysine glutarylation is a protein posttranslational modification regulated by SIRT5. Cell Metab. 19, 605-617 (2014).

25. Du, J. et al. Sirt5 is a NAD-dependent protein lysine demalonylase and desuccinylase. Science 334, 806-809 (2011).

26. Kaczmarska, Z. et al. Structure of p300 in complex with acyl-CoA variants. Nat. Chem. Biol. 13, 21-29 (2017).

27. Huang, $\mathrm{H}$. et al. p300-Mediated lysine 2-hydroxyisobutyrylation regulates glycolysis. Mol. Cell 70, 663-678.e666 (2018).

28. Candido, E. P., Reeves, R. \& Davie, J. R. Sodium butyrate inhibits histone deacetylation in cultured cells. Cell 14, 105-113 (1978).

29. Goudarzi, A. et al. Dynamic competing histone H4 K5K8 acetylation and butyrylation are hallmarks of highly active gene promoters. Mol. Cell $6 \mathbf{6}$, 169-180 (2016).

30. Parthun, M. R., Widom, J. \& Gottschling, D. E. The major cytoplasmic histone acetyltransferase in yeast: links to chromatin replication and histone metabolism. Cell 87, 85-94 (1996).

31. Nagarajan, P. et al. Histone acetyl transferase 1 is essential for mammalian development, genome stability, and the processing of newly synthesized histones H3 and H4. PLoS Genet. 9, e1003518 (2013).

32. Sirbu, B. M. et al. Analysis of protein dynamics at active, stalled, and collapsed replication forks. Genes Dev. 25, 1320-1327 (2011).

33. Gruber, J. J. et al. HAT1 coordinates histone production and acetylation via H4 promoter binding. Mol. Cell 75, 711-724.e715 (2019).

34. Bheda, P., Jing, $H$., Wolberger, C. \& Lin, $H$. The substrate specificity of sirtuins. Annu. Rev. Biochem. 85, 405-429 (2016).
35. Moreno-Yruela, C., Galleano, I., Madsen, A. S. \& Olsen, C. A. Histone deacetylase

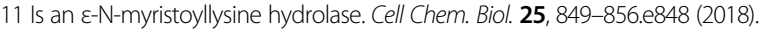

36. Seto, E. \& Yoshida, M. Erasers of histone acetylation: the histone deacetylase enzymes. Cold Spring Harb. Perspect. Biol. 6, a018713 (2014).

37. Eskandarian, H. A. et al. A role for SIRT2-dependent histone H3K18 deacetylation in bacterial infection. Science 341, 1238858 (2013).

38. Kwon, O. K., Kim, S. J. \& Lee, S. First profiling of lysine crotonylation of myofilament proteins and ribosomal proteins in zebrafish embryos. Sci. Rep. 8 3652 (2018).

39. Kollenstart, L. et al. Gen5 and Esa1 function as histone crotonyltransferases to regulate crotonylation-dependent transcription. J. Biol. Chem. 294, 20122-20134 (2019)

40. Zhang, Q. et al. Structural insights into histone crotonyl-lysine recognition by the AF9 YEATS Domain. Structure 24, 1606-1612 (2016).

41. Wang, $Y$. et al. KAT2A coupled with the a-KGDH complex acts as a histone H3 succinyltransferase. Nature 552, 273-277 (2017).

42. Wang, Y., Guo, Y. R., Xing, D., Tao, Y. J. \& Lu, Z. Supramolecular assembly of KAT2A with succinyl-CoA for histone succinylation. Cell Discov. 4, 47 (2018).

43. Xie, Z. et al. Lysine succinylation and lysine malonylation in histones. Mol. Cell Proteom. 11, 100-107 (2012).

44. Trefely, S., Lovell, C. D., Snyder, N. W. \& Wellen, K. E. Compartmentalised acylCoA metabolism and roles in chromatin regulation. Mol. Metab. 38, 100941 (2020).

45. Bachhawat, B. K., Coon, M. J., Kupiecki, F. P., Nagle, R. \& Robinson, W. G Coenzyme A thiol esters of isobutyric, methacrylic, and beta-hydroxyisobutyric acids as intermediates in the enzymatic degradation of valine. J. Biol. Chem. 224, 1-11 (1957).

46. Brownell, J. E. et al. Tetrahymena histone acetyltransferase A: a homolog to yeast Gcn5p linking histone acetylation to gene activation. Cell $\mathbf{8 4}, 843-851$ (1996).

47. Kleff, S., Andrulis, E. D., Anderson, C. W. \& Sternglanz, R. Identification of a gene encoding a yeast histone $\mathrm{H} 4$ acetyltransferase. J. Biol. Chem. 270, 24674-24677 (1995).

48. Nagarajan, P. et al. Early-onset aging and mitochondrial defects associated with loss of histone acetyltransferase 1 (Hat1). Aging Cell 18, e12992 (2019).

49. Marin, T. L. et al. AMPK promotes mitochondrial biogenesis and function by phosphorylating the epigenetic factors DNMT1, RBBP7, and HAT1. Sci. Signal. 10 (2017).

50. Brown, G. K. et al. beta-hydroxyisobutyryl coenzyme A deacylase deficiency: a defect in valine metabolism associated with physical malformations. Pediatrics 70, 532-538 (1982).

51. Loupatty, F. J. et al. Mutations in the gene encoding 3-hydroxyisobutyryl-CoA hydrolase results in progressive infantile neurodegeneration. Am. J. Hum. Genet. 80, 195-199 (2007).

52. Peters, $H$. et al. ECHS1 mutations in Leigh disease: a new inborn error of metabolism affecting valine metabolism. Brain 137, 2903-2908 (2014).

53. Colak, G. et al. Proteomic and biochemical studies of lysine malonylation suggest its malonic aciduria-associated regulatory role in mitochondrial function and fatty acid oxidation. Mol. Cell Proteom. 14, 3056-3071 (2015).

54. Pougovkina, O., Te Brinke, H., Wanders, R. J., Houten, S. M. \& de Boer, V. C. Aberrant protein acylation is a common observation in inborn errors of acylCoA metabolism. J. Inherit. Metab. Dis. 37, 709-714 (2014).

55. Xie, Z. et al. Metabolic regulation of gene expression by histone lysine $\beta$-hydroxybutyrylation. Mol. Cell 62, 194-206 (2016).

56. Fisher-Wellman, K. H. et al. Respiratory phenomics across multiple models of protein hyperacylation in cardiac mitochondria reveals a marginal impact on bioenergetics. Cell Rep. 26, 1557-1572.e1558 (2019).

57. Paik, W. K., Pearson, D., Lee, H. W. \& Kim, S. Nonenzymatic acetylation of histones with acetyl-CoA. Biochim. Biophys. Acta 213, 513-522 (1970).

58. Sivanand, S., Viney, I. \& Wellen, K. E. Spatiotemporal control of acetyl-CoA metabolism in chromatin regulation. Trends Biochem. Sci. 43, 61-74 (2018).

59. Shechter, D., Dormann, H. L., Allis, C. D. \& Hake, S. B. Extraction, purification and analysis of histones. Nat. Protoc. 2, 1445-1457 (2007).

60. $\mathrm{Wu}, \mathrm{H}$. et al. Structural basis for substrate specificity and catalysis of human histone acetyltransferase 1. Proc. Natl Acad. Sci. USA 109, 8925-8930 (2012). 